\title{
Results of experiments to determine the traction resistance of a disk working body
}

\author{
Rustem Sakhapov*, Ramil Gainutdinov, Marat Mahmutov, and Minsur Zemdikhanov \\ Kazan state University of Architectute and Engineering, 420043 Kazan, Russian Federation
}

\begin{abstract}
Technical means used for soil surface treatment do not fully meet the technical requirements for high-quality soil treatment. In order to solve this problem more effectively, various rotary machines with working bodies that perform complex spatial movement are currently being developed. But, as practice has shown, that the work of these tools is unstable and that the cultivation of the soil is carried out unevenly. To eliminate these disadvantages, we developed a tillage tool with ellipsoid disk working bodies mounted on the shaft at a strictly defined angle [7, 13]. The analysis showed that to ensure the efficiency of work and reduce the traction resistance of tools for tillage, it is necessary that the angle of installation of the ellipsoid disk abount rotation axis is also optimal. Here are the results of experimental studies of the traction resistance of disks conducted in the conditions of a soil channel. The mathematical model of the technological process was obtained by processing experimental data in the computer program "Statistica" and presented in the form of multiple regression equations in encoded and real physical quantities. The response surfaces are constructed based on the obtained equations.
\end{abstract}

\section{Introduction}

A mandatory part of the design stage of tillage machines and tools is to ensure the strength of structural elements, reduce energy consumption and determine the conditions for stable movement of equipment. Therefore, there is a need to determine the forces acting on the tool, the forces required for its movement on the surface of the processed field, i.e. in accordance with the generally accepted terminology - traction resistance.

To conduct laboratory research in accordance with the developed design and technological documentation and in accordance with the developed program, an experimental unit was created in the laboratory of the department. Experiments on measuring the traction resistance of an ellipsoid working body were carried out in the soil channel of the Kazan SAU $[2,5]$. The soil type is medium loamy, with average values of humidity, density, and soil hardness $-20.5 \%, 1.15 \mathrm{~g} / \mathrm{cm}^{3}$, and $1.4 \mathrm{MPa}$, respectively.

Significant contributions to the development and research of rotary tillage machines and tools were made by Goryachkin V.P. [2], Abdrakhmanov R.K. [1], Panov I.M. [12], Kanarev F.M. [8], Matyashin Yu.I. [11], Mazitov N.K. [10], Makarov P.I. [9], Sakhapov

\footnotetext{
*Corresponding author: rusakhapov@gmail.com
} 
R.L. [14 , 20, 21], Yakhin S.M. [16], Piotr F. B. [17], Soehne W. [18], Srivastava A. K. [19] et al.
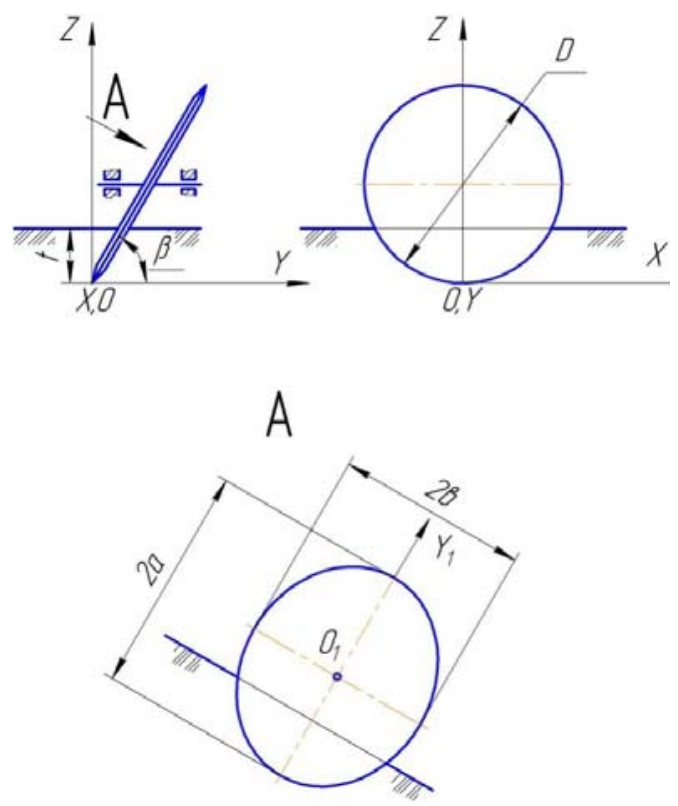

Fig. 1. Projections of an ellipsoid working body

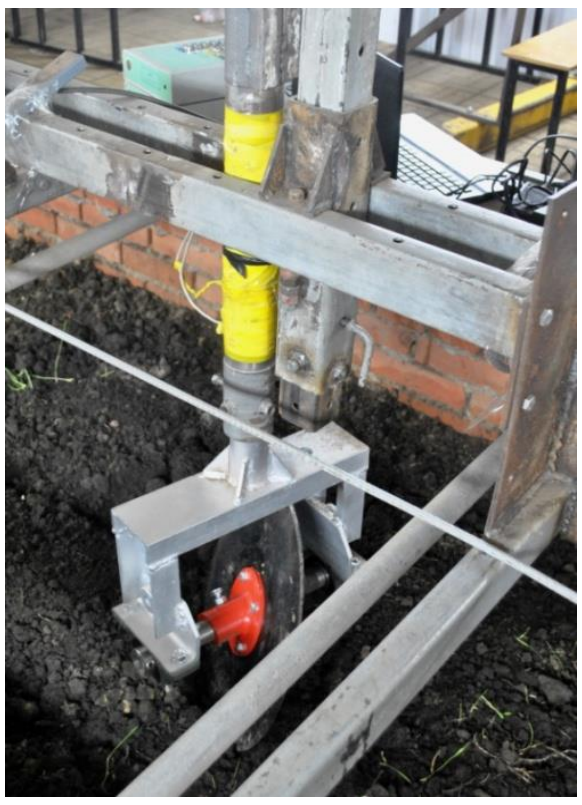

Fig. 2. Experimental unit

\section{Methods}

In accordance with the requirements of state and industry standards (GOST 24057-80, OST 70.2.15-73, OST 70.2.2-2002), experimental studies of the working body of the rotary tool, as well as its economic and energy assessment, were carried out in the laboratory.

Dynamometry is a reliable experimental method that can be used to determine the traction resistance of surface tillage tools [4]. The direct measurement method allows to get the value of the required parameter through the force measuring link, and the indirect measurement method - based on the results of any other characteristics measuring. An electronic dynamometer is used as a link for force measuring, and various sensors [15] connected to a working body or tool are used to implement indirect measurement methods.

The experimental device developed by us was installed in a separate deformable beam, which was attached to the frame of the cart. Strain gauge resistors of the brand KF5P1-15200 (hereinafter referred to as the load sensor) were installed on the beam in such a way that it was possible to measure the tensile strain, and therefore the traction resistance of the disk working body.

According to the prepared planning matrix, the experiment is repeated three times for different values of the tillage depth and the speed of ellipsoid disk movement. At the initial stage, in accordance with the operating instructions of the measuring information system IP 264 , strain gauge bridges were calibrated.

As it is known, when the experimental tool moves forward along the soil channel, the strain gauge beam is stretched, as a result of which the electrical resistance of the load sensor attached to it changes. The measuring information system IP 264 processes the signals received from the strain gauge bridges and transmits them to a personal computer. With the help of computer software the measurement results are displayed graphically. 
Then, taking the maximum values from the graphs using calibration data, they are converted to the unit of measurement - $\mathrm{N}$ (Newton).

When determining the traction resistance of an ellipsoid working body, the method of planning a complete factor experiment is used. Table 1 shows that the variable parameters of the experiments are as follows: working body speed (casrt) $-8,10,12 \mathrm{~km} / \mathrm{h}$, tillage depth (the depth of immersion of the working body in the soil) $-0.04 ; 0.06 ; 0.08 \mathrm{~m}$. As a result of data processing, a quantitative assessment of the influence of various factors on the traction resistance of the disk was obtained.

Table 1. Physical and coded levels of the experiment factors

\begin{tabular}{|c|c|c|c|c|c|c|c|c|}
\hline \multirow[t]{2}{*}{ Name of factors } & \multirow{2}{*}{$\begin{array}{l}\text { Designa } \\
\text { tion of } \\
\text { factors }\end{array}$} & \multirow{2}{*}{$\begin{array}{c}\text { Coded } \\
\text { designa } \\
\text { tion of } \\
\text { factors }\end{array}$} & \multicolumn{3}{|c|}{$\begin{array}{c}\text { Natural levels of } \\
\text { variation }\end{array}$} & \multicolumn{3}{|c|}{$\begin{array}{l}\text { Coded levels of } \\
\text { variation }\end{array}$} \\
\hline & & & $\begin{array}{l}\text { upp } \\
\text { er }\end{array}$ & basic & lower & upper & basic & $\begin{array}{c}\text { lowe } \\
\mathbf{r}\end{array}$ \\
\hline Tillage depth, $\mathrm{m}$ & $t$ & $\overline{X_{1}}$ & 0.08 & 0.06 & 0.04 & +1 & 0 & -1 \\
\hline $\begin{array}{ll}\begin{array}{l}\text { Forward speed, } \\
\mathrm{km} / \mathrm{h}\end{array} & \\
\end{array}$ & $V_{e}$ & $X_{2}$ & 12 & 10 & 8 & +1 & 0 & $\begin{array}{ll}-1 \\
\end{array}$ \\
\hline
\end{tabular}

The mathematical model of the technological process is compiled in the form of a linear multiple regression equation:

$$
Y=b_{0}+b_{1} X_{1}+b_{2} X_{2}+b_{12} X_{1} X_{2}+b_{11} X_{1} X_{1}+b_{22} X_{2} X_{2}
$$

where $Y$ - response function; $X_{1}, X_{2}$ - the first, the second factors of the process under study, $b_{0}$ - characterizing the values of the response function $Y$ in the centre of the plan; $b_{1}, b_{2}$ - coefficients characterizing the degree of influence of the first and second factors on response function $Y ; b_{12}, b_{11}, b_{22}-$ - coefficients characterizing the significance of the influence of relevant factors on the response function $Y$.

Table 2. Experiment planning matrix

\begin{tabular}{|c|c|c|c|c|}
\hline \multirow{2}{*}{$\begin{array}{c}\text { Number } \\
\text { of experiment }\end{array}$} & \multicolumn{2}{|c|}{ Natural experiment factors } & \multicolumn{2}{c|}{ Coded experiment factors } \\
\cline { 2 - 5 } & $t$ & $V_{\mathrm{e}}$ & $X_{1}$ & $X_{2}$ \\
\hline 1 & 0.04 & 8 & -1 & -1 \\
\hline 2 & 0.06 & 8 & 0 & -1 \\
\hline 3 & 0.08 & 8 & +1 & -1 \\
\hline 4 & 0.04 & 10 & -1 & 0 \\
\hline 5 & 0.06 & 10 & 0 & 0 \\
\hline 6 & 0.08 & 10 & +1 & 0 \\
\hline 7 & 0.04 & 12 & -1 & +1 \\
\hline 8 & 0.06 & 12 & 0 & +1 \\
\hline 9 & 0.08 & 12 & +1 & +1 \\
\hline
\end{tabular}

\section{Results and Discussion}

The results of the experiments are presented in table 3 .

Table 3. Results of experiments on determining the traction resistance of the ellipsoid disk in soil channel

\begin{tabular}{|c|c|c|c|c|}
\hline \multirow{2}{*}{$\begin{array}{c}\text { Experiment } \\
\text { number }\end{array}$} & \multicolumn{4}{|c|}{ Traction resistance of ellipsoid disk, N } \\
\cline { 2 - 5 } & $Y_{1}$ & $Y_{2}$ & $Y_{3}$ & $Y_{c p i}$ \\
\hline 1 & 125.38 & 177.71 & 104.90 & 135.99 \\
\hline
\end{tabular}




\begin{tabular}{|l|l|l|l|l|}
\hline 2 & 201.11 & 173.88 & 196.42 & 190.47 \\
\hline 3 & 323.09 & 219.85 & 204.0 & 248.98 \\
\hline 4 & 150.28 & 185.62 & 112.54 & 149.48 \\
\hline 5 & 176.13 & 221.18 & 228.25 & 208.52 \\
\hline 6 & 216.36 & 260.21 & 334.51 & 270.36 \\
\hline 7 & 177.80 & 140.57 & 171.61 & 163.32 \\
\hline 8 & 199.11 & 238.59 & 258.78 & 232.16 \\
\hline 9 & 303.80 & 369.19 & 287.66 & 320.21 \\
\hline
\end{tabular}

As a result of using the computer program Statistica for processing experimental data, the following encoded mathematical model of multiple regression is obtained:

$$
Y=225.5747-394.7083 X_{1}-33.4501 X_{2}+10850.004 X_{1} X_{1}++1.4337 X_{2} X_{2}+274.375 X_{1} X_{2}
$$

Analysis of the standard form of the regression equation shows that the parameter $Y$ is most affected by the mixed factor $X_{1} X_{2}$, since the coefficient of the equation that characterizes it is 0.923 , and this is the largest coefficient in this equation. The calculated value of the Student's criterion is less than its threshold value $(0.0061<0.05)$, which indicates that the parameters of the mathematical model have statistical significance [3].

The validity of the mathematical model is confirmed by the Fisher criterion and its calculated value is 5.3. It was determined that the coefficient of determination $R^{2}=$ $0,9984^{2}=0.9968$, that is, it occupies $99.68 \%$ of the total variability $\mathrm{Y}$ in the studied process due to changes in the factors $X_{1}$ and $X_{2}$. Taking into account the degrees of freedom, the tabular value of the Fisher criterion is 9.01. Therefore, since the following condition $5.3<9.01$ is met, the coefficient of determination is statistically reliable, and the regression equation is statistically reliable.

The mathematical model of the technological process was obtained in the form of a multiple regression equation in real physical quantities by evaluating the importance of the studied factors and taking into account their interrelation:

$$
Y=241.365-789.4167 t-33.45 V_{e}+10850 t^{2}+1.4337 V_{e}^{2}+274.375 t V_{e}
$$

The regression equation is analyzed statistically with a $95 \%$ confidence probability of the experiment. Table 4 shows the results of the analysis. The designations indicated here are the following: $Y_{c p i}$ - average experimental value of the traction resistance of the working body; Y - traction resistance of the working body according to the multiple regression equation (3); $\varepsilon$ - unbiased error; $\varepsilon^{2}$ - dispersion of traction resistance; $\left|\varepsilon / Y_{c p i}\right|$ module of the absolute error of approximation.

Table 4. Statistical analysis of the multiple regression equation

\begin{tabular}{|c|c|c|c|c|c|}
\hline No. & $\boldsymbol{Y}_{\mathrm{cp} \boldsymbol{i}}$ & $\boldsymbol{Y}$ & $\boldsymbol{\varepsilon}=\boldsymbol{Y}_{\mathrm{cp} \boldsymbol{i}} \boldsymbol{Y}$ & $\varepsilon^{\mathbf{2}}$ & $\left|\boldsymbol{\varepsilon} / \boldsymbol{Y}_{\mathrm{cp} \boldsymbol{i}}\right|$ \\
\hline 1 & 135.99 & 139.105 & -3.115 & 9.701 & 0.0229 \\
\hline 2 & 190.47 & 188.916 & 1.554 & 2.414 & 0.00816 \\
\hline 3 & 248.98 & 247.408 & 1.572 & 2.471 & 0.00631 \\
\hline 4 & 149.48 & 145.769 & 3.711 & 13.772 & 0.0248 \\
\hline 5 & 208.52 & 206.556 & 1.964 & 3.859 & 0.00942 \\
\hline 6 & 270.36 & 276.022 & -5.662 & 32.062 & 0.0209 \\
\hline 7 & 163.32 & 163.903 & -0.583 & 0.34 & 0.00357 \\
\hline 8 & 232.16 & 235.665 & -3.505 & 12.284 & 0.0151 \\
\hline 9 & 320.21 & 316.107 & 4.103 & 16.839 & 0.0128 \\
\hline \multicolumn{7}{|c|}{ Total values of indicators } \\
\hline
\end{tabular}

Subsequently, the value of the absolute approximation error modulus, which is the deviation of the experimental values of the traction resistance from its theoretical values, is used to assess the reliability of the experiment $[1,6]$. 
Table 4 shows that the total value of the absolute approximation error of the experiment is 0.124 . Therefore, the average value of this indicator is- $(0.124 / 9) \cdot 100=1.38 \%$. The results of the experiment are reliable, since the average value of the absolute approximation error does not exceed $10 \%$.

\section{Conclusions}

The multiple regression equation and the obtained experimental data allow to construct the response surface of the mathematical model (Fig. 3 and 4). From these figures, it can be concluded that as the speed of movement and the depth of tillage increases, the traction resistance of the ellipsoid disk working body also increases.

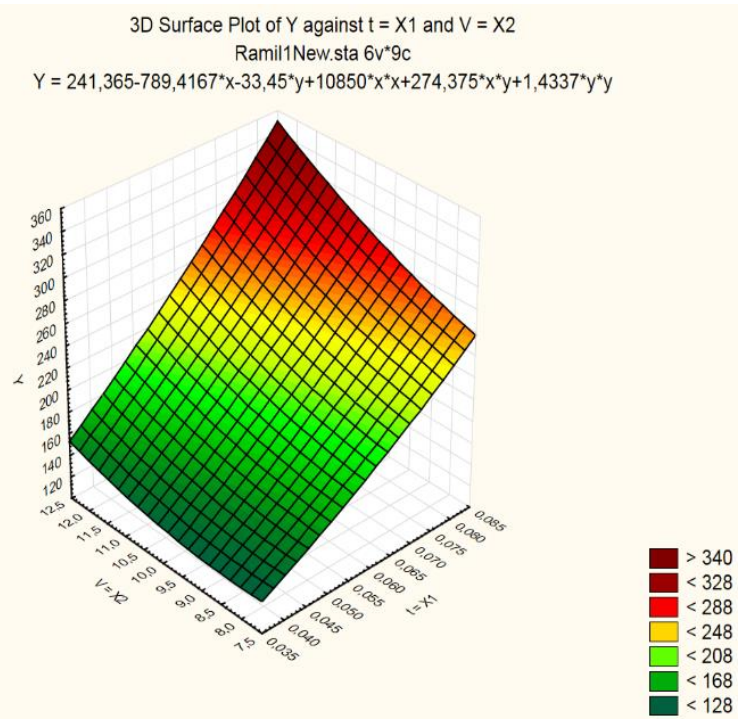

Fig. 3. Response surface by the multiple regression equation

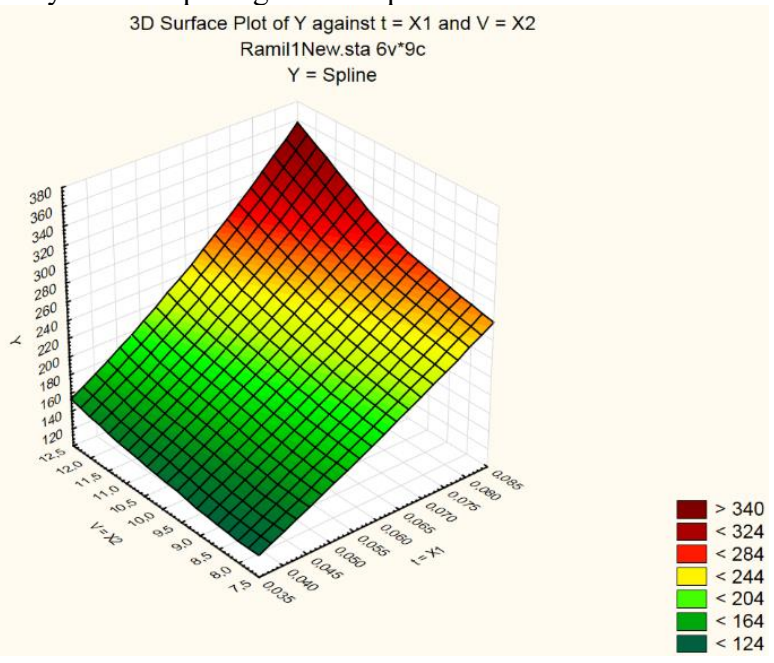

Fig. 4. Response surface by the experimental data

When the depth of the soil, equal to $0.08 \mathrm{~m}$, and translational speed of the cart is 12 $\mathrm{km} / \mathrm{h}$ traction resistance of rotary tools ellipsoid disc amounted to $320.2 \mathrm{~N}$. For comparison, 
with the minimum parameter values respectively $0.04 \mathrm{~m}$ and $8 \mathrm{~km} / \mathrm{h}$, underlying the experiment, the traction resistance was $135.9 \mathrm{~N}$.

And so, an increase in the translational speed of the disk working body leads to a sharp increase in its traction resistance. Consequently, from energy and economic considerations, the most expedient is the area for tillage at a depth of $0.08 \mathrm{~m}$ and a speed of $10-11 \mathrm{~km} / \mathrm{h}$.

\section{References}

1. R.K. Abdrakhmanov, Machines and tools for inter-row tillage (Design, theory, calculation, operation) (Kazan: Kazan SAUY, 2001)

2. V.P. Goryachkin, Collected works, 1, 720 (Moscow: Kolos, 1968)

3. A.F. Bermant, G. Aramanovich, Short course of mathematical analysis (I- Saint Petersburg: "Lan", 2005)

4. R.Kh. Gaynutdinov, S.M. Yakhin, I.I. Aliakberov, Bulletin of the Kazan SAU, 2(40), 64-67 (2016)

5. R.Kh. Gaynutdinov, Bulletin of the Kazan SAU, 1(43), 71-75 (2017)

6. R.Kh. Gaynutdinov, S.M. Yakhin, I.I. Aliakberov, G.V. Pikmullin, Machinery and equipment for the village, 8(230), 10-14 (2016)

7. B.G. Ziganshin, S.M. Yakhin, R.Kh. Gaynutdinov, Bulletin of the Bashkir SAU, 2(42), 71-74 (2017)

8. F.M. Kanarev, Rotary tillage machines and tools (Moscow: Mashinostroenie, 1983)

9. P.I. Makarov, The scientific basis of the technology and rotary machines for the smooth processing of soil, abstract of Diss. Doctor of Tech. Sciences, (Moscow: VIM, 2000)

10. N.K. Mazitov, Soil and machines, (Kazan: Tatknigoizdat, 1988)

11. Yu.I. Matyashin, I.M. Grinchuk, G.M. Egorov, Calculation and design of rotary tillage machines (Moscow: Agropromizdat, 1988)

12. I.M. Panov, Mechanical and technological bases of calculation and design of machines with rotary working bodies: Diss. Doct. Techn. Sciences: (M.: All-Union Institute of Agricultural Engineering, 1983)

13. S.M. Yakhin, I.I. Aliakberov, R.Kh. Gaynutdinov, Patent of the Russian Federation for the invention dated 3.05.2018 No. 2652819, Disk tool for surface tillage, (Russia)

14. R.L. Sakhapov, N.K. Mazitov, R.S. Rakhimov, Ya.P. Lobachevsky, N.Kh. Galyautdinov, L.Z. Sharafiev, Machinery and equipment for the village, 3(189), 2-6 (2013)

15. M.M. Firsov, M.M. Makhmutov, V.I. Slavkin, Tractors and agricultural machines, 6, 14-16 (2015)

16. S.M. Yakhin, Kh. Gaynutdinov, R.Kh. Mardanov, Rural machine operator, 6, 8-9 (2017)

17. F.B. Piotr, Marek Klimkiewicz, Małgorzata Powałka, Selected problems of soil tillage systems and operations (Warsaw: WEMA. Warsaw University of Life Sciences, 2010)

18. W. Soehne, Canadian Journal of Agricultural Engineering, 5(1), 2-3 (1963)

19. Srivastava, Ajit K., Carroll E. Goering, Roger P. Rohrbach, Dennis R., Soil tillage, Chapter 8 in Engineering Principles of Agricultural Machines (St. Joseph, Michigan: ASABE, 2006) 
20. R. Sakhapov, M. Makhmutov, IOP Conference Series: Materials Science and Engineering, 786, 012038 (2020) 10.1088/1757-899X/786/1/012038

21. R. Sakhapov, M. Makhmutov, IOP Conference Series: Materials Science and Engineering, 786, 012021 (2020) 10.1088/1757-899X/786/1/012021 